УдК: 330.341 .1

\title{
ПРИЧИНЫ ПЕРЕХОДА К НОВОМУ ТЕХНОЛОГИЧЕСКОМУ УКЛАДУ
}

\author{
О.А. НАУМОВИЧ
}

Старший научный сотрудник сектора промышленной политики отдела инновационной политики Института экономики НАН Беларуси

\section{Аннотация}

Рассмотрены некоторые причины смены технологических укладов в экономике Республики Беларусь, выявлена их взаимообусловленность. В процессе исследования изучены предпосылки, а также последствия смены технологического уклада.

Abstract

Certain causes of the change of technological structures in the economy of the Republic of Belarus, found their interdependence. The study examined the prerequisites and consequences of the change of technological way.

\section{ВВЕДЕНИЕ}

Современное развитие экономики в Республике Беларусь критически зависимо от успешности перехода к новому технологическому укладу. Необходимо отказаться от традиционных научных взглядов и практических подходов к участию белорусских предприятий в международном трансфере технологий, опирающихся на либерально-рыночный миф о том, что рыночная экономика «автоматически» обеспечивает получение современных технологий от стран технологических лидеров. Реалии последних десятилетий показали, что это не так. Уровень технологического развития страны напрямую зависит от эффективности государственного конфигурирования национальной модели развития. Республика Беларусь может обеспечить технологический прорыв в отечественной промышленности только при условии сознательного государственного регулирования рыночных отношений в интересах перехода к инновационному развитию отрасли на основе научно обоснованных подходов и механизмов.

\section{РЕЗУЛЬТАТЫ И ИХ ОБСУЖДЕНИЕ}

Сложившаяся относительно устаревшая структура экономики, имеющая разрыв в технологических цепочках производства выражается в сокращении объемов выпуска, занятых и услуг. Промышленности нужны автоматизированные станки, новое технологическое оборудование, высококвалифицированная рабочая сила. Недостаток высококвалифицированных инженеров является критичным для промышленности. Снижение доли внешних инвестиций нацеливает на организацию процесса внутреннего накопления, увеличение доли капитальных вложений в ВВП, нормализацию кредитования производства с высокой добавленной стоимостью.

С одной стороны, невозможность реализации предприятиями собственных инноваций, а с другой - зависимость от внешних рынков блокируют научно-техническое развитие. Проблема видится в кризисе самой экономической системы, которая подрывает стимулы и потенциал высокотехнологичных преобразований. Необходимо восстановление отдельных ликвидированных видов производств, жизненно важных для отечественной индустрии. Пробелы заполняются импортной техникой, иногда бывшей в употреблении и отстающей по развитию от мировых аналогов. Поэтому курс на заимствование ошибочен и губителен для высокотехнологичной модернизации отечественной экономики. Для решения этой проблемы необходимо создать государственный сектор, располагающий передовыми технологическими разработками, научно-техническими разработками и проводившими политику наукоемкого развития. Российский экономист О. Сухарев в качестве важнейших показателей научно-технического развития верно выделил «реальные достижения в области машиностроения, электроники, трудосбережения и энергоэффективности» [9, с. 29]. Машиностроение обеспечивает создание эффективных станков и оборудования. Отечественное машиностроение не может удовлетворять потребностям в высокотехнологичном оборудовании, поэтому приходится импортировать, вытесняя тем самым отечественных производителей.

Создание передового высокотехнологичного производства должно стимулироваться и контролироваться государством при активном участии социально-научного сообщества, т.к. от развития этого сектора экономики зависит конкурентоспособность, национальная безопасность, будущее развитие науки. Поэтому важно определить приоритетные направления, по которым возможно занять новое положение в мире.

Высокотехнологичные производства сыграли решающую роль в новом толчке к экономическому росту в наиболее развитых странах. Новые технологии сегодня оказывают влияние на сектор услуг. Наблюдается снижение доли материального производства и увеличение сектора услуг, т.к. «сервисная экономика постиндустриального типа в меньшей степени нуждается в привлечении дополнительных материальных ресурсов для обеспечения экономического роста. При этом она несравненно более зависима от накопления интеллектуальных ресурсов, новых технологий и информации» [6, с. 158]. Становление нового технологического уклада сопровождается ростом информационного сектора и сферы услуг. Отличительной чертой услуги от товара является ее зависимость от исполнителя, квалификация которого влияет на качество услуги и ее способность, в конечном счете, удовлетворять потребностям потребителя. 
Путем модернизации производственной базы, информатизации процессов производства, повышения доли услуг и наукоемких производств в структуре ВВП возможно сформировать новый высокотехнологичный уклад и за счет перечисленных мероприятий повысить конкурентоспособность страны. Развитие базирующейся на новых технологиях сферы услуг и общее повышение жизненного уровня превращают спрос на услуги и обеспечивающие их технологии в мощный локомотив экономического роста. Благодаря быстрому росту производства и постоянному обновлению информационных технологий, они становятся ведущими товарами и услугами производства и потребления и занимают все возрастающую долю в общем объеме ВВП. Увеличение экспортного потенциала сектора услуг является важным направлением структурной перестройки. Республика Беларусь может предоставлять услуги в сфере транспорта, логистики, информационных технологий, образования, здравоохранения, спорта, культуры, туризма и т.д.

Главное конкурентное преимущество в настоящем и будущем - это интеллектуальный потенциал страны, формирование которого должно рассматриваться как приоритетная задача. Совершенствование механизма продвижения наиболее талантливых представителей всех слоев общества в управленческую и интеллектуальную элиту предполагает ввод в нее не только новых людей, но и новых идей, поскольку «высокий инновационный потенциал становится < ...> важнейшим фактором конкурентной борьбы...» [3].

Для поддержания высоких темпов экономического роста необходимо повышение производительности труда, улучшение качества оказываемых услуг, привлечение прямых иностранных инвестиций за счет внедрения новых технологий. Экспорт услуг в Республике Беларусь, по сравнению с 2005 г. (2 342 млрд. дол. США), в 2012 г. вырос в 2,8 раза и составил 6646 млн. дол. США, импорт услуг увеличился в 3,4 раза и составил 3842 млн. дол. США. Экспорт товаров по сравнению с 2005 г. (15 194 млрд. дол. США), увеличился в 3 раза (45 244 млрд. дол. США). Сальдо из отрицательного (-860) в 2012 г. стало положительным [1].

Производство лазерно-оптической техники ориентировано на выпуск конкурентоспособной наукоемкой продукции. Лазерно-оптическая промышленность Республики Беларусь впускает 0,31 \% от мирового объема данной продукции при численности населения 0,148 \% общемировой.

Оборот высокотехнологичной продукции на мировом рынке в несколько раз превышает оборот сырья. На данный момент в Республике Беларусь доля экспорта и импорта высокотехнологичной продукции остается низкой. Поэтому для реализации стратегии инновационного развития в ближайшей перспективе необходимо делать упор на продукцию с высокой добавленной стоимостью. Экспорт белорусских высокотехнологичных товаров наибольший удельный вес в общем экспорте занимал в 2002 г. (4,29\%) [1]. В 2008 г. этот показатель достиг минимального значения за последнее десятилетие и составлял 2,4 \%, а стал максимальным - 3,04 \% в 2010 г. [1]. В денежном выражении общая сумма высокотехнологичного экспорта постоянно увеличивается. Так, с 217 млн. дол. США в 2002 г. экспорт вырос до 407 млн. дол. США в 2010 г. [2].

Формально высокотехнологичными считаются отрасли (согласно классификации ОЭСР), в которых «показатель наукоемкости (отношение затрат на НИОКР (научно-исследовательские и опытно-конструкторские работы) к продажам) превышает 3,5 \%» [5, с. 215], если этот показатель превышает 8,5 \%, то они характеризуются как «ведущие» наукоемкие технологии [5, с. 215]. Понятия «наукоемкости» и «высокотехнологичности» следует разграничивать, т.к. они выделяются по разным критериям. В наукоемких производствах доля затрат на науку должна составлять не менее 3,5 \%, а высокотехнологичные отрасли характеризуются массовым применением передовых технологий. Поэтому не все высокотехнологичные отрасли являются наукоемкими. Следует отметить, что с учетом начального этапа становления высокотехнологичного уклада отсутствуют отрасли, полностью состоящие из высокотехнологичных производств.

Согласно Методическим рекомендациям по отнесению производств к высокотехнологичным (в том числе к производствам V и VI технологических укладов) от 14.09.2010 г. [7] к производствам пятого технологического уклада относятся производства «в сфере аэрокосмической, радиоэлектронной промышленности, роботостроения и приборостроения, вычислительной и оптиковолоконной техники, разработки программного обеспечения, телекоммуникаций, производства и переработки газа, информационных услуг, а также биотехнологий, производства фармацевтической продукции, медицинской техники» [7]. К VI технологическому укладу, согласно указанным методическим рекомендациям, могут относиться производства в следующих сферах: «производства наноэлектроники, молекулярной и нанофотоники, наноматериалов и наноструктурированных покрытий, оптических наноматериалов, наногетерогенных систем, нанобиотехнологий, наносистемной техники, нанооборудования, водородной энергетики, систем искусственного интеллекта, а также производства на основе использования клеточных технологий, методов генной инженерии» [7]. Из перечня высокотехнологичных производств можно отметить, что к ним относятся отрасли, обладающие высокой инновационной активностью. По мировым критериям к высокотехнологичному укладу относятся VI и VII технологические уклады (в основе которых приборо- и роботостроение, биокомпьютерные системы и биомедицина, т.е. связь искусственных и органических, «живых» систем).

Разработка инновационной продукции требует значительных инвестиций и может осуществляться в основном только на базе критических (прорывных, пионерных) технологий. Использование критических технологий должно служить как целям импортозамещения, так и конкуренции на мировых рынках. Создание принципиально новых производств, отраслей, производство высокотехнологичной продукции - главный путь развития национальной экономики на ближайшую пятилетку. Для этого обеспечен благоприятный бизнес-климат для инвесторов.

Основной источник экономического роста в развитых странах мира переместился в сторону накопления научных знаний, воплощенных в технологических нововведениях. Технологический подъем формирует ряд новых отраслей хозяйства, соответственно, меняет и потребности людей, общественное сознание в целом. Переход к постинду- 
стриальной стадии развития определяет основные ориентиры социально-экономического развития Республики Беларусь, происходит переориентация на современные наукоемкие отрасли, меняется структура экономики. Приоритет отдается экологическим и информационным императивам. Поскольку большую часть отраслевой структуры составляют производства IV, V, кое-где III технологических укладов. Целесообразным представляется в отраслях III и IV укладов скачок к производству шестого технологического уклада, где это возможно, а где нет - замена отрасли в целом. Уровень инновационно активных предприятий остается пока невысоким, около 16 \%. В Республике Беларусь имеются некоторые разработки мирового уровня, но их недостаточно для осуществления инновационного прорыва. Возрастают шансы при осуществлении совместных разработок, в первую очередь, с Россией по направлениям, которых разработок в мире нет, а не пытаться идти по пути «догоняющего» развития. Начало таких разработок уже положено. Таким образом, посредством достижения взаимосвязей между образованием, наукой, промышленностью, необходимого воздействия новшеств возможно построение технологических цепочек нового технологичного уклада.

Выпускаемая в рамках высокотехнологичного уклада продукция позволяет совершенствовать все остальные разновидности конкретного труда, добиваться повышения их результативности и в целом приводить к росту производительности труда. Так, за последние пять лет производительность труда выросла на 17\%, что можно отметить как положительную тенденцию при переходе к новому укладу. Потребление высокотехнологичной продукции создает экономию общественного труда и тем самым обеспечивает прирост национального дохода. Таким образом, социально-экономический эффект функционирования высокотехнологичного уклада выражается в кардинальных изменениях во всех элементах производительных сил: в средствах и предметах труда, в рабочей силе, в серьезных сдвигах в их качестве, степени совершенства, эффективности. Основной целью перехода к новому технологическому укладу является достижение социально-экономического эффекта, понимаемого как снижение издержек, уменьшение негативного влияния на экологию, соблюдение ресурсоемкости, улучшение потребительных характеристик.

Качественные преобразования могут осуществляться за счет активной промышленной политики государства, сохранения исходных преимуществ национальной экономики и возникновения новых конкурентных преимуществ на высокотехнологичной основе. Развитие отраслей промышленности тесно связано между собой, так как конечный продукт одной отрасли является промежуточным продуктом другой. В то же время стагнация в одних отраслях может повлечь отставание и свертывание производства в других. Если в XIX веке самой крупной отраслью промышленности являлась текстильная, то на смену ей пришли химическая, металлургическая и машиностроение. Постепенно эти отрасли стали сближаться с наукой. Труд профессиональных ученых стал более полезным и экономически выгодным. Структура промышленного производства меняется за счет развития наукоемких, высокотехнологичных производств при уменьшении роли ряда традиционных отраслей. Быстрое развитие высокотехнологичных отраслей связано с увеличением численности занятых в них, что способно обеспечить переход к новой модели экономического роста.

Задача белорусской экономики заключается в осуществлении высокотехнологичной модернизации всех отраслей экономики. Необходимо возрождение роли машиностроения, повышения его наукоемкости, насыщение электронной промышленностью, выпуск современной продукции, которая позволит модернизировать остальные отрасли. Основной упор модернизации должен быть на материальное производство, т.к. новые направления научно-технического прогресса формируются на материально-технической основе. Эффективным представляется их масштабное внедрение.

Преимуществом технологической отсталости является возможность использования технологических и институциональных достижений развитых стран для более быстрого и дешевого рывка, т.е. не повторять открытия «передовиков», а перешагнуть через них. Однако такой «прыжок» представляется весьма рискованным для нашей страны, т.к. может привести к кратковременному успеху. Наиболее приемлемой для Беларуси представляется стратегия последовательного промышленного развития. Перенесение технологий может осуществляться, главным образом, посредством интеграции в транснациональные экономические структуры. Во время трансформации индустриальной экономики в постиндустриальную происходит пересмотр роли институциональных факторов. На первое место выдвигаются факторы, связанные с инновационным развитием среды людей, способности к генерированию новых знаний. Знания являются более производительным ресурсом, чем какой-либо другой ресурс. Дж. Гэлбрейт в свое время писал, что «доллар, вложенный в образование, приносит больший прирост национального дохода, чем доллар, вложенный в железные дороги, плотины, машины и другие материальные блага» [4, с. 49]. Система институтов оказывает влияние на освоение и внедрение новых технологий и инноваций, т.е. способствует экономическому росту.

\section{ВЫВОДЫ}

Основной проблемой социально-экономического развития Республики Беларусь является выход из индустриальной эпохи и формирование социально-технологических основ постиндустриального общества. Для этого необходимо выработать стратегию социально-экономического прорыва. Эта задача является достаточно сложной, т.к. факт перехода к постиндустриальному обществу не гарантирует успешности достижения страной поставленных целей. Ключевыми являются проблемы развития человека, инвестиции в человеческий капитал, а, соответственно, конкурентными преимуществами обладают факторы, обеспечивающие жизнедеятельность человека, - образование, здравоохранение, инфраструктура. 


\section{ЛИТЕРАТУРА}

1. High-technology exports (\% of manufactured exports) // The World Bank [Electronic resource]. - Mode of access : http://data.worldbank.org/indicator/ BX .GSR CCIS.ZS. - Date of access : 11.04.2012.

2. High-technology exports (current US\$) // The World Bank [Electronic resource]. - Mode of access : http://data.worldbank.org/indicator/TX.VAL.TECH. MF.ZS?display=default. - Date of access : 13.04.2012.

3. Глазьев, С.Ю. Стратегия опережающего развития России в условиях глобального кризиса / С.Ю. Глазьев. - М. : Экономика, 2010. - 255 с.

4. Гэлбрейт, Д. Экономические теории и цели общества : пер. с англ. / Д. Гэлбрейт ; под ред. Н.Н. Иноземцева, А.Г. Милейковского. - М. : Прогресс, 1979. - 406 с.

5. Пелих, С.А. Государство и экономика : избр. науч. тр. : в 3 т. / С.А. Пелих ; Акад. упр. при Президенте Респ. Беларусь. - Минск : Право и экономика, 2011. - Т. 3. - 551 с.

6. Перепелкин, В.А. Структурные изменения в процессе экономического роста / В.А. Перепелкин ; Рос. акад. наук, Самар. науч. центр Рос. акад. наук. - Самара : Самар. науч. центр РАН, 2005. - 424 с.

7. Положение о порядке конкурсного отбора инновационных проектов, научно-исследовательских, опытноконструкторских, опытно-технологических работ и отнесения производств (проектов) к высокотехнологичным // Официальный интернет-портал Минского горисполкома [Электронный ресурс]. - 2011. - Режим доступа http://minsk.gov.by/ru/actual/view/338 - Дата доступа: 01.06.2011.

8. Солодовников, С.Ю. Экономическая обусловленность эволюции социально-классовой структуры общества переходного периода / С.Ю. Солодовников. - Минск : Белорус. гос. экон. ун-т, 1999. - 149 с. C. $22-30$.

9. Сухарев, О.С. Промышленность: кризис и перспективы развития / О.С. Сухарев // Экономист. - 2011. - № 2. -

Статья поступила в редакиию 29 июня 2015 года. 